Nanosecond Ultrasonics to Study Phase Transitions in Solid and Liquid Systems at High Pressure and Temperature

B. P. Bonner, P. A. Berge, S. C. Carlson, D. L. Farber, J. Akella

April 13, 2007 
This document was prepared as an account of work sponsored by an agency of the United States Government. Neither the United States Government nor the University of California nor any of their employees, makes any warranty, express or implied, or assumes any legal liability or responsibility for the accuracy, completeness, or usefulness of any information, apparatus, product, or process disclosed, or represents that its use would not infringe privately owned rights. Reference herein to any specific commercial product, process, or service by trade name, trademark, manufacturer, or otherwise, does not necessarily constitute or imply its endorsement, recommendation, or favoring by the United States Government or the University of California. The views and opinions of authors expressed herein do not necessarily state or reflect those of the United States Government or the University of California, and shall not be used for advertising or product endorsement purposes.

This work was performed under the auspices of the U.S. Department of Energy by University of California, Lawrence Livermore National Laboratory under Contract W-7405-Eng-48. 
FY06 LDRD Final Report

\title{
Nanosecond Ultrasonics to Study Phase Transitions in Solid and Liquid Systems at High Pressure and Temperature
}

\author{
LDRD Tracking Code: 04-ERD-033
}

Brian P. Bonner, Principal Investigator

\section{P.A. Berge, S.C. Carlson, D.L.Farber and J. Akella, Co-Investigators}

\begin{abstract}
This report describes the development of a high-frequency ultrasonic measurement capability for application to the study of phase transitions at elevated pressure and temperature. We combined expertise in various aspects of static high-pressure technique with recent advances in wave propagation modeling, ultrasonic transducer development, electronic methods and broadband instrumentation to accomplish the goals of this project. The transduction and electronic systems have a demonstrated bandwidth of $400 \mathrm{MHz}$, allowing investigations of phenomena with characteristic times as short as $2.5 \mathrm{nS}$. A compact, pneumatically driven moissanite anvil cell was developed and constructed for this project. This device generates a high-pressure environment for $\mathrm{mm}$ dimension samples to pressures of $3 \mathrm{GPa}$. Ultrasonic measurements were conducted in the moissanite cell, an LLNL multi-anvil device and in a modified piston cylinder device. Measurements for water, and elemental tantalum, tin and cerium demonstrate the success of the methods. The $\gamma$ - $\alpha$ phase transition in cerium was clearly detected at $\sim 0.7 \mathrm{GPa}$ with 75 $\mathrm{MHz}$ longitudinal waves. These results have direct application to important problems in LLNL programs, as well as seismology and planetary science.
\end{abstract}

\section{Introduction}

Recent innovations in ultrasonic and high-pressure methods provide an opportunity to improve equation-of-state (EOS) and thermodynamic information for metals, alloys and other materials of scientific and programmatic interest. Better material properties data can then be used to validate detailed simulations of dynamic phenomena based on sophisticated material descriptions, or on $a b$-initio approaches. At present, material models used in numerical simulations are evolving from simple, but robust approaches that can be directly verified by experience to more comprehensive models that require detailed understanding of material response. Phase transitions pose a particular challenge for simulations and experiments, and were the particular focus of this project. Ultrasonic measurements potentially provide a sensitive means to monitor the transformation process, so that more complete models of material behavior at extreme conditions can include improved descriptions of transformations.

Ultrasonics measurements can also answer important questions about the composition and thermodynamic state of the earth and other planetary bodies. For example, high quality elastic constant and attenuation data for minerals and metals (iron and its alloys in particular) are essential for comparisons with whole earth seismic data. 
Ultrasonic interferometry was developed originally for precise (travel-times to 1 part in $10^{5}$ ) measurement of elastic properties (McSkimin, 1950, 1961). The erd003method was adapted to high pressure to study small $(<1 \mathrm{~mm})$ samples of highly attenuating earth materials undergoing phase changes (Katz and Ahrens, 1963). Ultrasonic methods were used for measuring attenuation and velocity values (to about 1 part in $10^{3}$ ) in multi-component rock melts (e.g., Katahara et al., 1981). Success in such a complex, highly attenuating system demonstrates the potential of the method. Measurements of velocity dispersion (e.g., Feller et al., 1999) and frequency-dependent attenuation (e.g., Zhu and Zheng, 2000) are sensitive to details of structure, such as ordering and spin-phonon interactions. Ultrasonics also was used to study properties near phase transitions (e.g., Stenger and Trivisonno, 1998; Zhu and Zheng, 2000), complex shear modulus and viscosity in films to a minimum thickness of 10 microns (Alig et al., 1997). High frequency ultrasound can characterize rapid microscopic processes, such as kink formation in dislocations and can detect nucleation of a second phase by exploiting changes in elastic constants and attenuation. Recent advances in high-frequency digital electronics, transducers adapted from ultrasonic microscopy, and modern computers have yielded improvements in the ultrasonic method that allow measurements on samples smaller than 100 microns at frequencies up to 1.5 $\mathrm{GHz}$ with travel time precision to about 1 part in $10^{5}$ (Spetzler and Yoneda, 1993; Spetzler et al., 1993, 1996).

\section{Apparatus Development}

We developed three new ultrasonic measurement systems to address the specific challenges that arose during the course of the project. These are all broadly defined as contact ultrasonic methods, and provide a precise and accurate means of determining sound velocities in solids and liquids when physical contact with the sample is possible, either directly or through a buffer rod. All three rely on electronics with nanosecond or better rise times, efficient transducers that operate up to near $\mathrm{GHz}$ frequencies, and signal processing software to demodulate the time history of the detected ultrasonic energy. Maximum system bandwidth enables measurements for shorter path lengths (<100 microns, Challis et al., 1992; Hanneman and Kinra, 1992) with sufficiently short characteristic times to investigate the energetics of rapid processes. Capabilities for smaller sample sizes inherently enable measurements at higher pressure (Bassett et al., 2000).

In all three configurations, high-frequency sound waves are transmitted to a sample, and the reflected waves are detected and timed with appropriate broad band electronics to collect data on frequency-dependent sound velocity and attenuation in the material held under high pressure and/or high temperature conditions. A functional block diagram of the electronic components common to all systems is given as Figure 1. A measurement proceeds as follows. The process begins with a fast trigger pulse that initiates data acquisition and triggers a high voltage transducer excitation. The piezoelectric transducer, which typically operates in frequency range from 50 to $225 \mathrm{MHz}$, generates either a longitudinal or transverse wave that travels through the buffer rod to the sample. After an appropriate delay, introduced by the buffer rod, the low level return echoes are detected by the same transducer. The measured elapsed time between the buffer and sample echoes and the transit path length determines the velocity of the appropriate mode. The attenuation of that mode can be determined if two or more echoes are detected. The frequency dependence of the velocity determines the acoustic dispersion of the mode. Ultrasonic frequencies of between 10 and $400 \mathrm{MHz}$ provide broad bandwidth for dispersion measurements. The pulse repetition rate is of the order of $1 \mathrm{kHz}$, so that signal averaging is typically applied to 
increase the signal-to-noise ratio. High sampling rates $(2 \mathrm{GHz})$ and long buffer memories enable all the ultrasonic methods, interferometry, pulse echo overlap, or sing around, for example, that required specialized hardware for implementation in the past.

Next, we focus on the details of the geometry of each configuration. A moissanite (the mineral name for single crystal $\mathrm{SiC}$ ) anvil cell was designed and constructed for this project. The ultrasonic arrangement is shown as Figure 2a. A fused silica buffer rod transmits longitudinal waves into the gasketed sample chamber. The sample chamber is 1.5 to $2 \mathrm{~mm}$ in diameter and $\sim 0.5 \mathrm{~mm}$ high. This geometry produces strong returns from the sample buffer rod interface with little dispersion arising from the slender buffer rod. The opposing anvil and the mechanical supporting structures are omitted for clarity.

The ultrasonic configuration for the D-DIA multi-anvil experiments is shown in Figure 2b. (The D-DIA acronym signifies D for deformation and DIA for diamond because this cubic anvil design was first used for diamond synthesis at high pressure and temperature.) The ultrasonic measurements were done with the LLNL D-DIA in collaboration with B. Li of SUNY Stony Brook at the NSLS at Brookhaven National Laboratory. In this case, a multi-mode $50 \mathrm{MHz}$ $\mathrm{LiNbO}_{3}$ transducer was used, so that both longitudinal and shear waves were launched and detected. The electronic configuration was as in Figure 1, but with the addition of waveform processing that uses the 'transfer function' method developed by Li. The D-DIA ultrasonic configuration (Wang et al., 2003) improves on the arrangement used by Li et al., 1996. In the DDIA configuration, the pressure surrounding the sample can be adjusted for hydrostaticity by moving the D-DIA uniaxial pistons to achieve hydrostatic lattice strains in the $\mathrm{NaCl}$ pressure medium. Sample length is directly measured with simultaneous radiography that takes advantage of the bright flux of the synchrotron. The samples are $\sim 1 \mathrm{~mm}$ by $\sim 1 \mathrm{~mm}$ right cylinders or rectangular parallelepipeds of similar volume. The remaining five anvils, as well as the supporting structures, are not shown here for clarity.

The piston cylinder configuration is shown in Figure 2c. In this case, longitudinal waves are transmitted through the loading piston to the sample, which is surrounded with a cold-pressed $\mathrm{NaCl}$ ring to create a 'quasi hydrostatic' stress distribution. The samples are right cylinders or discs with diameters of $\sim 12 \mathrm{~mm}$ and lengths of $\sim 1 \mathrm{~mm}$ to $20 \mathrm{~mm}$. Usable sample length depends primarily on intrinsic attenuation as well as the interrogation frequency. The echo from the piston sample interface depends on the piston length, which decreases during loading. Since the piston remains elastic during the experiment, the travel time in the piston can be used as a secondary pressure standard. The time difference between the piston interface echo, the echo from the other side of the sample, and the sample length determine the longitudinal velocity at pressure. The sample length is estimated from piston displacement, independent measurements of the elastic constants with appropriate assumptions about the boundary conditions, or from finite element simulation of the assembly.

Each of the three ultrasonic configurations were installed in the specialized high pressure apparatus to create the sample environment for measurements. The moissanite anvil cell is a compact, self-contained portable unit constructed specifically for this project in collaboration with F. Occelli and D. Ruddle. The cell was dimensioned for beam line compatibility and can be transported easily to synchrotrons or neutron sources so that complementary measurements can 
be made simultaneously with ultrasonics. A photograph of the assembled cell is shown as Figure 3a. It is approximately $100 \mathrm{~mm}$ in diameter and is constructed of high strength steel. The highpressure tubing exiting the cell at the top provides nitrogen gas to drive the pistons in opposition with pneumatic drive. The anvils, transparent with a greenish hue, and with a metal gasket between them, appear in the center of the photograph. Figure $3 \mathrm{~b}$ shows the cell before assembly to reveal individual components. Two of the steel tie rods that react the anvil driving force are shown in the lower left. The bottom of the cell, with guide pins and one tie rod in place is shown in the left center. The bottom moissanite anvil was previously shown schematically in the first ultrasonic configuration, Figure 2a. The mounting plate for the top anvil is shown in the lower right of Figure $3 \mathrm{~b}$. This view shows the steel support ring for the moissanite, a brass centering ring, and the top of the tungsten carbide hemispherical seat on which the anvil rests. The seat can be rotated for anvil alignment, and provides the strength needed to support anvils at the highest loads. The top loading plate, seen upright in the upper right of Figure $3 \mathrm{~b}$ includes the pressurized gas chamber that drives the anvils to generate pressure. The gas driven loading system is capable of generating sufficient force to produce $30 \mathrm{GPa}$ on appropriately sized anvils. The 'donut' shaped ring is a 'membrane' of stainless steel closed with electron beam welds that seals the gas and flexes to apply pressure. Conical openings in both upper plates allow optical access to the pressure chamber during experiments. Figure $3 \mathrm{c}$ is a photograph of a typical moissanite anvil. The material is single crystal silicon carbide with hardness second only to diamond. The $3 \mathrm{~mm}$ diameter cullet forms the lower margin of the pressure chamber for ultrasonic measurements.

The pressure generation and mechanical support systems for D-DIA experiments is illustrated in Figures 4a-c. The photograph of Figure 4a shows the self-contained D-DIA assembly ready for placement in the $400 \mathrm{~T}$ load frame that drives the guide blocks and wedges to produce all around confining pressure. X-ray access is in the plane of the four horizontal wedges, through the low atomic number gasketing material that is placed between the anvils. The bottom anvil assembly is shown removed from the apparatus in Figure 4b. A tungsten carbide anvil, showing placement of a piezoelectric transducer for ultrasonic measurements, is on the left. The tungsten carbide anvils have been replaced by boron nitride or sintered diamond for improved X-ray access. Xrays are used both to determine the sample length at pressure for velocity calculations and for Bragg diffraction of the $\mathrm{NaCl}$ pressure medium. Measurement of the lattice distortion of the $\mathrm{NaCl}$, along with the known equation of state, determines the pressure in the sample chamber. Operation of the D-DIA is shown schematically in Figure 4c. First, pressurizing the main rams increases the sample chamber pressure by driving the platens together. Then the differential rams, which are nested inside the assembly, are moved independently of the main ram to generate differential pressure and sample deformation. In ultrasonic experiments, the differential rams can be used to balance small deviations from hydrostatic conditions to ensure uniform compression of the sample. The design pressure for the apparatus is $15 \mathrm{GPa}$, but measurements are routinely done to $\sim 7 \mathrm{GPa}$. The samples are $\sim 1 \mathrm{~mm}$ by $\sim 1 \mathrm{~mm}$ right cylinders or rectangular parallelepipeds of similar volume. A complete description of the apparatus, without modifications for ultrasonic experiments, is given by Wang et al., 2003.

The third apparatus pressurizes the piston cylinder ultrasonic configuration of Figure $2 \mathrm{c}$ and is shown in Figures 5a and 5b. A long distance view of the $300 \mathrm{~T}$ load frame set up for a hydraulic test and calibration is shown in Figure 5a. The large light blue hydraulic ram at the bottom of the figure applies clamping pressure to the tungsten carbide core of the pressure vessel shown in 
Figure 2c. The pressure vessel is a multi-wall design, with an inner core of tungsten carbide. This core must be kept in compression by clamping during experiments. The smaller blue ram, which is seen more clearly in Figure 5b, drives the piston from the bottom into the vessel to generate pressure on the sample. The pressure vessel of the type used in the ultrasonic measurements appears in the center of Figure $5 \mathrm{~b}$ and can be identified by the horizontal brass rods used as lifting fixtures. The steel cylinder below the vessel is a 'bridge' that carries the clamping force from the main ram to load the core of the pressure vessel during loading. This system is capable of producing $3 \mathrm{GPa}$ on an $18 \mathrm{~mm}$ nominal piston, but the ultrasonic configuration is limited to 1.2 GPa to preserve apparatus components for multiple use. Pressures are computed from readings of hydraulic pressure in the small ram that determine force on the sample and the area of the sample chamber cross section.

\section{Results}

Ultrasonic propagation in water enabled us to determine the overall system bandwidth, including the electronic systems and transducers, as shown in Figure 1. Water is an ideal material for calibration purposes. Sound propagation in water is well-characterized, and it has an acoustic quality factor $\mathrm{Q}$ in excess of $10^{5}$ and weak velocity dispersion in the frequency range of interest. The series of measurements with variable paths of $\sim 3 \mathrm{~mm}$ to a $\mathrm{SiO}_{2}$ reflector show low loss propagation (Figure 6). Spectral analysis indicates good signal to noise to over $400 \mathrm{MHz}$ enabling us to investigate dynamic phenomena with characteristic times of $\sim 2.5 \mathrm{~ns}$ or longer with this system. These tests were done in collaboration with S. Benson.

We also used the fourth order elastic finite difference code E3D (Larsen et al., 2001) to model details of the experimental ultrasonic configurations for guidance in experimental design and as an aid in interpretation. An example of a result obtained with a line of impulsive sources to simulate a plane wave incident on $\mathrm{BeCu}$ and water layers is shown in Figure 6 . The simulation was of an idealized version of the moissanite anvil configuration of Figure 2a. The main goal of the simulation was to evaluate the acoustic performance of different metal gaskets. The simulated time series in the top of the figure gives the time history of ultrasonic interactions between the moissanite ( $\mathrm{SiC}$ ) single crystal and a $\mathrm{BeCu}$ gasket. The first return shows that little energy is reflected at the interface, and therefore will not interfere significantly with the sample return in the actual test configuration. $\mathrm{BeCu}$ is therefore a promising gasket material for ultrasonics, although gasket strength is also a consideration. The lower trace shows interaction with a water sample. The amplitude difference in the return from the water sample is much larger than that from the $\mathrm{BeCu}$, consistent with the large acoustic impedance differences between water and moissanite. The details of the reflection depend on the elastic and dispersive properties of incident and output layers. The reflection from the water to moissanite interface at the far side of the simulated sample did not appear in the simulation. The baseline noise that increases with time in the second time series, presumably from improper handling of boundary reflections or numerical errors, obscures the return. Most of the other reflections in the time series are artifacts of the simulation geometry. Similar reflections are also seen in all physical experiments, and the sample geometry must be chosen to avoid them whenever possible.

Experiments with the moissanite anvil cell ultrasonic configuration that tested water samples were in qualitative agreement with the simulations. Strong returns were received from the moissanite water interface at high pressure. Data were obtained below and above the liquid-to- 
Ice VI transition at $\sim 0.9 \mathrm{GPa}$. The ice VI phase was clearly identified optically through the top anvil. The occurrence and nature of the transition are consistent with independent measurements, but the return from the far side of the sample was not identified unambiguously. However, the density of both phases is well known, so the frequency-dependent acoustic impedance and velocity dispersion at pressure can be recovered with additional experiments using system identification methods. Therefore, the configuration of Figure 2a has strong potential for characterizing materials at high pressure in difficult measurements where impedance contrasts are strong.

Both longitudinal and shear waves at $50 \mathrm{MHz}$ were observed for polycrystalline tantalum with the ultrasonic configuration for the D-DIA (Figure 2b). Tantalum is a transition metal with BCC structure that remains stable to $100 \mathrm{GPa}$. The assembly was fitted with an internal furnace in this case so that data could be collected at simultaneous high temperature and pressure. A record of a longitudinal wave packet at $3 \mathrm{GPa}$ is reproduced in Figure 8. Echoes from the anvil end of the buffer rod and sample are distinctly separated. The waveform is characteristic of Li's 'transform function method' in which the transducer is excited by a $\sin \mathrm{x} / \mathrm{x}$ excitation voltage, but the asymmetry to longer times suggests a parasitic transducer resonance. Quality longitudinal returns were obtained up to $6 \mathrm{GPa}$ and $600^{\circ} \mathrm{C}$, but shear arrivals were less consistent. The measurements were performed in collaboration with B. Li of SUNY Stony Brook at the NSLS at Brookhaven National Laboratory, enabling simultaneous X-ray measurements of sample length under highpressure temperature conditions with radiography. Sample lengths can be determined to $0.1 \mu \mathrm{m}$, yielding an accuracy of $0.01 \%$ for a nominal $1 \mathrm{~mm}$ sample. A small chip of polycrystalline tantalum was placed in the pressure medium to permit simultaneous Bragg diffraction, eliminating the need to measure pressure indirectly and determining the elastic constants of tantalum as a function of volume directly. Further details of the results appear in Li, 2007.

We used the piston cylinder ultrasonic configuration of Figure $2 \mathrm{c}$ with the assistance of J. Siebert to investigate the soft metals, tin and cerium. These metals have high ultrasonic attenuation that makes measurements challenging. We began with tin because polycrystalline samples can be formed by cold pressing, and oxide free samples are easier to prepare from powder since tin resists oxidation. Tin exists in multiple phases, but we limited our investigation to $\beta$-tin, a centered tetragonal form stable at room temperature and pressure. At 9.2 GPa tin transforms to $\gamma$ tin, a denser centered tetragonal phase. We were able to build assemblies that provided usable returns for $3 \mathrm{~mm}$ samples of the beta phase to pressures of $\sim 0.2 \mathrm{GPa}$. The pressure vessel was fitted with a chiller to access the transition to $\alpha$-tin, the semi-conducting cubic diamond phase, but technical difficulties caused to us to defer the effort to examine that semiconductor to metal transition.

Higher pressure experiments were necessary for cerium. Cerium undergoes an isostructural (fcc) $\gamma-\alpha$ volume collapse of $\sim 17 \%$ at room temperature at a pressure $\sim 0.8 \mathrm{GPa}$. Cerium is a prime example of a material with ambiguous electronic behavior. The $4 \mathrm{f}^{1}$ electron exists near the boundary of localized and itinerant behavior. There has been considerable recent discussion about the origins and nature of phase transitions in this unusual circumstance (Jeong et al., 2004 and many others). 
Remarkably, the only previous ultrasonic measurements at pressure for cerium appear to be those of Voronov et al., 1960. This may be due in part to difficulties in handling and preparing cerium for testing. The metal is brittle and rapidly oxidizes in air. The Voronov et al. results are unusual in that the velocity of the longitudinal mode, measured at 3.5 to $5.5 \mathrm{MHz}$, decreases monotonically from zero pressure as pressure increases in the $\gamma$ phase. The transverse mode velocity is essentially independent of pressure for the $\gamma$ phase, first increasing slightly and then slowly decreasing. The high pressure $\alpha$ phase that appears near $0.76 \mathrm{GPa}$, according to Voronov et al., shows more normal behavior, with increases in both mode velocities with pressure. Although this observation is consistent with the anomalous decrease in compressibility with pressure reported by Bridgman (1964), several details of the measurement raise questions. First, the Voronov et al. sample was only $98.5 \%$ pure, and alloying alters the character of the transition, as discussed by Bridgman and subsequent authors. Secondly, Voronov et al. note that degradation of the transducer-specimen ultrasonic bond caused difficulty with their measurements of transit times for transverse waves, particularly in the vicinity of the phase change. Their calculation of the sample length from stepwise integration of the measured bulk modulus depends on reliable values for both longitudinal and transverse times. If the transverse time is systematically over-estimated, the computed path length will be biased low, and high if the opposite occurs. It is possible that this effect could explain at least part of the anomaly in the velocity of the longitudinal mode.

Our experiments for cerium avoid these potential difficulties. In our configuration, the normal stress at the buffer rod-sample interface is always nearly equal to the pressure, guaranteeing a good ultrasonic bond to the sample. We obtained higher purity (99.9\%) cerium polycrystals, and loaded them rapidly after final polishing into the piston cylinder configuration to avoid excessive oxidation. We detected quality ultrasonic returns to $1.2 \mathrm{GPa}$ (12 kilobars or 180,000 psi). The reciprocal of the measured longitudinal travel time for our nominal $2 \mathrm{~mm}$ sample is plotted as a function of pressure in Figure 9. The pressure measurement is accurate to $\pm 0.05 \mathrm{GPa}$ in this configuration. Our location of the transition pressure is consistent with Voronov et al. and more recent estimates of the transition pressure as $0.8 \mathrm{GPa}$ (Jeong et al., 2004).

The plotted reciprocal transit time is proportional to the velocity of the longitudinal mode differing only by a scaling factor for sample length. The decrease in longitudinal velocity associated with the $\gamma-\alpha$ phase transition is clearly evident in the data. We have not corrected for change in sample length with pressure to emphasize that the change in velocity dominates the coincident change in length. For hypothetical constant velocity, a decrease in path length would increase the reciprocal time. Therefore, the actual anomalous drop in reciprocal time near the transition is underestimated in the plot. The reciprocal time decreases $\sim 4 \%$ and the measurement precision is $>1 \%$ with signal averaging. The vertical line marks the approximate pressure of the phase transition according to Voronov et al. In agreement with Voronov et al., the transit time becomes time-dependent in the vicinity of the phase transition. Waiting times of 0.1 to 2 hrs are needed to achieve nearly steady transit time values. Above $1 \mathrm{GPa}$, the time dependence becomes negligible. Increases in reciprocal time with pressure occur in the $\alpha$ phase region, as is typical for a fully dense solid. We extended measurements to $1.2 \mathrm{GPa}, 0.3 \mathrm{GPa}$ higher than Voronov et al., and the reciprocal time increases monotonically with increasing pressure. The $\alpha$ phase persists for several tenths of $\mathrm{GPa}$ into the $\gamma$ region upon unloading. Voronov et al. also reported velocity hysteresis in the transition region. Direct comparison is difficult because few details are given 
by Voronov et al., but it appears that the nature of the hysteresis is different in our measurements. The pressure interval for time dependent behavior appears to be shorter, and equilibration times are more rapid in our experiments. Several factors might contribute to these differences. Our test configuration imposes some shear stress on the sample (their's was hydrostatic) and our measurement frequency is higher. The longitudinal mode softens before the transition, but the transverse mode behavior is also anomalous, suggesting a mechanism that may show some sensitivity to shear stress. In addition, the broadband ultrasonic excitation for our measurements was centered at $75 \mathrm{MHz}$. Although attenuation in the sample limited the output frequency content of the signal return, our experiments clearly sample shorter spatial scales than the 3.5 to $5.5 \mathrm{MHz}$ measurements of Voronov et al. It is likely that the macroscopic stress state will affect the texture of the cerium in the two-phase region, which could alter the ultrasonic signature. These topics are discussed in Bonner et al., 2007.

\section{Exit Plan}

Improved equation-of-state (EOS) and thermodynamic information for metals, alloys and other materials are of continuing and abiding interest to many DOE NNSA programs, and we expect that these programs will continue this effort. Better material properties data are valuable for improving and extending detailed simulations of dynamic phenomena based on increasingly sophisticated material descriptions and for validation of ab-initio approaches. Phase transitions pose a particular challenge for simulation and experiment. The ultrasonic modalities developed in this project provide a sensitive means to monitor the transformation process, so that more complete models of behavior at extreme conditions could include improved descriptions of transformations. Material property measurements at pressure and temperature provide a basis for further understanding of the earth and other planetary bodies. The DOE Office of Science funds efforts in these areas, and the methods developed in this project enable competitive proposals on these topics.

\section{Summary}

We report the development and demonstration of a robust, versatile capability for conducting measurements of sound velocities under the challenging conditions that accompany phase transitions. The ultrasonic system bandwidth is $\sim 400 \mathrm{MHz}$, and the system can investigate phenomena with characteristic times from $\sim 1 \mu \mathrm{S}$ to $2.5 \mathrm{nS}$. Phenomena with shorter characteristic times, to $1 \mathrm{nS}$, could be examined with straight-forward modifications to piezoelectric transducers and electronic components. We used the elastic finite difference code, E3D, developed originally for seismic applications, to simulate experiments and as an aid for apparatus configuration design. We developed and/or applied three functional ultrasonic configurations for successful measurements in response to the technical challenges that arose during the experiments. Large differences in acoustic impedance and attenuation for the variety of samples of interest required different experimental solutions. One ultrasonic configuration operates in a moissanite anvil cell conceived, designed, constructed and demonstrated for this project. The second uses the LLNL D-DIA in a collaborative effort, initiated by this project with B. Li of SUNY at Stony Brook, that enables measurements at simultaneous high pressure and temperature. The third adapts the piston cylinder apparatus for ultrasonic measurements. The piston cylinder accepts a wide variation in sample length and is capable of broadband measurements, making it optimal for highly attenuating or dispersive samples. The combined design pressure/temperature capabilities of the three systems are $20 \mathrm{GPa}$ and $2000^{\circ} \mathrm{C}$, but we did 
not approach these values in this effort in order to preserve components for multiple experiments. The moissanite anvil cell developed for this project provides a means to create a hydrostatic, high-pressure environment for samples with mm dimensions.

We report the capabilities of the apparatus for materials with widely different acoustic impedances and attenuations, with ultrasonic results for tantalum, water, Ice VI, tin and cerium. The cerium results clearly show the effects of the $\gamma$ - $\alpha$ volume collapse (fcc) at $\sim 0.8 \mathrm{GPa}$ on the longitudinal sound mode. This result is in broad agreement with the single previous measurement of Voronov et al., 1960 for $98.5 \%$ pure material. Differences in the character of the ultrasonic anomaly suggest that there may be an effect on the transition due to impurity content or macroscopic stress state, since our measurements are for $99.9 \%$ pure cerium and our measurements were not purely hydrostatic.

\section{Acknowledgements}

We are grateful to C. Aracne, who solved the challenges associated with preparation of cerium samples. This work was performed under the auspices of the U. S. Department of Energy (DOE) by the University of California, Lawrence Livermore National Laboratory (LLNL) under Contract No. W-7405-Eng-48. The project (04-ERD-033) was funded by the Laboratory Directed Research and Development Program at LLNL. 


\section{References and Biblliography:}

Ahrens, T. J., and S. Katz, 1962, An ultrasonic interferometer for high-pressure research, Journal of Geophysical Research, 67, 2935-2944.

Ahrens, T. J., and S. Katz, 1963, Ultrasonic observation of the calcite-aragonite transition, Journal of Geophysical Research, 68, 529-537.

Alig, I., Lellinger, D., Sulimma, J., and Tadjbakhsch, S., 1997, Ultrasonic shear wave reflection method for measurements of the viscoelastic properties of polymer films, Review of Scientific Instruments, 68, 1536-1542.

Anderson, O. L., and E. Schreiber, 1965, The pressure derivatives of the sound velocities of polycrystalline magnesia, Journal of Geophysical Research, 70, 5241-5248.

Auld, B. A., 1973, Acoustic Fields and Waves in Solids, Vol. 1 and 2, John Wiley \& Sons, New York.

Bassett, W. A., Reichmann, H.-J., Angel, R. J., Spetzler, H., and Smyth, J. R., 2000, New diamond anvil cells for gigahertz ultrasonic interferometry and X-ray diffraction, American Mineralogist, 85, 283-287.

Berge, P. A., 1991, Estimating SV-wave stacking velocities for transversely isotropic solids: Geophysics, 56, 1596-1602.

Berge, P. A., Fryer, G. J., and Wilkens, R. H., 1992, Velocity-porosity relationships in the upper oceanic crust--Theoretical considerations: J. Geophys. Res., 97, 15239-15254.

Berryman, J. G., 1995, Mixture theories for rock properties, in Ahrens, T. J., Ed., Rock physics and phase relations: A handbook of physics constants: American Geophysical Union, 205-228.

Berryman, J. G., and Berge, P. A., 1996, Critique of two explicit schemes for estimating elastic properties of multiphase composites: Mechanics of Materials, 22, 149-164.

Bonner, B. P., Boro, C., and Hart, D. J., 1999, Anti-waveguide for ultrasonic testing of granular media under elevated stress, LLNL Patent disclosure IL-10607, and patent application, DOE Patent Docket No. S-94182, October 28, 1999.

Bonner, B. P., et al., 2007, Characterizing the $\gamma$ - $\alpha$ phase transition in Cerium with high frequency ultrasound, in preparation.

Bridgman, P. W., 1964, Collected Experimental Papers, Harvard University Press, Cambridge.

Challis, R. E., Cocker, R. P., Holmes, A. K., and Alper, T., 1992, Viscoelasticity of thin adhesive layers as a function of cure and service temperature measured by a novel technique, J. Applied Polymer Sci., 44, 65-81. 
Chen, G., Spetzler, H. A., Getting, I. C., and Yoneda, A., 1996, Selected elastic moduli and their temperature derivatives for olivine and garnet with different $\mathrm{Mg} /(\mathrm{Mg}+\mathrm{Fe})$ contents: Results from GHz ultrasonic interferometry, Geophysical Research Letters, 23, 5-8.

Cynn, H., and Yoo, C.-S., 2000, Elasticity of tantalum to $105 \mathrm{GPa}$ using a stress and angleresolved x-ray diffraction, in Manghnani, M. H., Nellis, W. J., and Nicol, M. F., Eds., Science and Technology of High Pressure, Proceedings of the AIRAPT-17, Universities Press, Hyderabad, India, 432-435.

Duffy, T. S., Shen, G., Shu, J., Mao, H.-K., Hemley, R. J., and Singh, A., 1999, Elasticity, shear strength, and equation of state of molybdenum and gold from x-ray diffraction under nonhydrostatic compression to $24 \mathrm{GPa}$, Journal of Applied Physics, 86, 6729-6736.

Farber, D.L., Williams, Q., and Ryerson, F. J., 1994, Chemical diffusion in $\mathrm{Mg}_{2} \mathrm{SiO}_{4}$-polymorphs at high-pressure: Implications for chemical heterogeneity in the transition zone, Nature, 371, 693-695.

Farber D. L., Q. Williams, and F. J. Ryerson, 2000, Diffusion measurements in high-pressure phases: Implications for electrical conductivity in the upper mantle, Journal of Geophysical Research, 105:(B1) 513-529.

Feller, J. R., Dasgupta, D., Zhang, N., Hinks, D. G., Ketterson, J. B., and Sarma, B. K., 1999, Velocity dispersion at the metamagnetic transition in $\mathrm{UPt}_{3}$, Physica B, 261, 656-657.

Fiquet, G., M. Krisch, F. Guyot, J. Badro, C. Bellin, H. Requardt, A. Mermet, and J. Zhang, 2001a, Application of inelastic x-ray scattering to measurements of acoustic wave velocities in geophysical materials at very high pressure, proceedings of the EUG XI Symposium on the Geochemistry, Structure, and Dynamics of the Earth's Mantle, C. Ballentine, M. Rehkamper, and D. Price, Eds., Strasbourg, France, April 2001.

Fiquet, G., J. Badro, F. Guyot, H. Requardt, and M. Krisch, 2001b, Sound velocities in Fe to 110 GPa, Science, 291, 468.

Funamori, N., Jeanloz, R., Nguyen, J. H., Kavner, A., Caldwell, W., Fujino, K., Miyajima, N., Shinmei, T., and Tomioka, N., 1998, High-pressure transformation in $\mathrm{MgAl}_{2} \mathrm{O}_{4}$, J. Geophys. Res., 103, 20813-20818.

Hanneman, S. E., and Kinra, V. K., 1992, A new technique for ultrasonic nondestructive evaluation of adhesive joints: Part I. Theory, Experimental Mechanics, December 1992 issue, 323-331.

Jackson, I., Niesler, H., and Weidner, D. J., 1981, Explicit correction of ultrasonically determined elastic wave velocities for transducer-bond phase shifts, Journal of Geophysical Research, 86, 3736-3748. 
Jeong, L-K., T. W. Darling, M. J. Graf, Th. Proffen, R. H. Heffner, Yongjae Lee, T. Vogt and J. D. Jorgensen, 2004, Role of the lattice in the $\mathrm{g}-\mathrm{a}$ phase transition of Ce: A high pressure neutron and x-ray diffraction study, Phys. Rev. Lett, 92, 105702.

Katahara, K. W., M. H. Manghnani, and E. S. Fisher, 1976, Pressure derivatives of the elastic moduli of niobium and tantalum, Journal of Applied Physics, 47(2), 434-439.

Katahara, K. W., M. H. Manghnani, and E. S. Fisher, 1979a, Pressure derivatives of the elastic moduli of BCC Ti-V-Cr, Nb-Mo and Ta-W alloys, J. Phys. F: Metal Phys., 9(5), 773-790.

Katahara, K. W., M. Nimalendran, M. H. Manghnani, and E. S. Fisher, 1979b, Elastic moduli of paramagnetic chromium and Ti-V-Cr alloys, J. Phys. F: Metal Phys., 9(11), 2167-2176.

Katahara, K. W., Rai, C. S., Manghnani, M. H., and Balogh, J., 1981, An interferometric technique for measuring velocity and attenuation in molten rocks, Journal of Geophysical Research, 86, 11,779-11,786.

Katz, S., and Ahrens, T. J., 1963, Ultrasonic measurements of elastic properties of small specimens at high pressure, and Discussion, in Giardini, A. A., and Lloyd, E. C., Eds., HighPressure Measurement, Proceedings of the High-Pressure Measurement Symposium at the Winter Annual Meeting of the American Society of Mechanical Engineers(ASME), held in New York City, November, 1962, sponsored by ASME, Butterworths, Washington, D. C., pp. 246261.

Kohn, V. G., Chumakov, A. I., and Ruffer, R., 1998, Nuclear resonant inelastic absorption of synchrotron radiation in an anisotropic single crystal, Physical Review B, 58, 8437-8444.

Krisch, M. H., A. Mermet, A. San Miguel, F. Sette, and C. Masciovecchio, 1997, Acousticphonon dispersion in CdTe at 7.5 GPa, Physical Review B, 56(14), 8691-8694.

Larsen, S., Wiley, R., Roberts, P., and L. House, 2001, Next-generation numerical modeling: incorporating elasticity, anisotropy and attenuation, Lawrence Livermore National Laboratory Report UCRL-JC-142910, 6 pp.

Lheureux, D., F. Decremps, M. Fischer, A. Polian, J. P. Itie, G. Syfosse, and A. Zarembowitch, 2000, Ultrasonics and X-ray diffraction under pressure in the Paris-Edinburgh cell, Ultrasonics, $38,247-251$.

Li, B., I. Jackson, T. Gasparik, and R. C. Liebermann, 1996, Elastic wave velocity measurement in multi-anvil apparatus to $10 \mathrm{GPa}$ using ultrasonic interferometry, Physics of the Earth and Planetary Interiors, 98, 79-91.

Li, B., Liebermann, R. C., and Weidner, D. J., 1998, Elastic moduli of wadsleyite ( $\left.\beta-\mathrm{Mg}_{2} \mathrm{SiO}_{4}\right)$ to 7 gigapascals and 873 Kelvin, Science, 281, 675-677.

$\mathrm{Li}$, B., 2007, Elastic moduli of tantalum to $5 \mathrm{GPa}$ and $600^{\circ} \mathrm{C}$, in preparation. 
Mao, H.-k., Shu, J., Shen, G., Hemley, R. J., Li, B., and Singh, A. K., 1998, Elasticity and rheology of iron above $220 \mathrm{GPa}$ and the nature of the Earth's inner core, Nature, 396, 741-743. (See correction to this paper, 1999, Nature, 399, 280.)

McSkimin, H. J., 1950, Ultrasonic measurement techniques applicable to small solid specimens, Journal of the Acoustical Society of America, 22, 413-418.

McSkimin, H. J., 1961, Pulse superposition method for measuring ultrasonic wave velocities in solids, Journal of the Acoustical Society of America, 33, 12-16.

Niesler, H., and Jackson, I., 1989, Pressure derivatives of elastic wave velocities from ultrasonic interferometric measurements on jacketed polycrystals, Journal of the Acoustical Society of America, 86, 1573-1585.

Rai, C. S., M. H. Manghnani, and K. W. Katahara, 1981, Ultrasonic studies on a basalt melt, Geophysical Research Letters, 8(12), 1215-1218.

Reichmann, H. J., S. D. Jacobsen, S. J. Mackwell, and C. A. McCammon, 2000, Sound wave velocities and elastic constants for magnesiowustite using gigahertz interferometry, Geophysical Research Letters, 27(6), 799-802.

Schreiber, E., and O. L. Anderson, 1966, Temperature dependence of the velocity derivatives of periclase, Journal of Geophysical Research, 71, 3007-3012.

Secco, R. A., M. H. Manghnani, and T.-C. Liu, 1991a, The bulk modulus-attenuation-viscosity systematics of diopside-anorthite melts, Geophysical Research Letters, 18(1), 93-96.

Secco, R. A., M. H. Manghnani, and T.-C. Liu, 1991b, Velocities and compressibilities of komatiitic melts, Geophysical Research Letters, 18(8), 1397-1400.

Singh, A. K., Balasingh, C., Mao, H.-k., Hemley, R. J., and Shu, J., 1998, Analysis of lattice strains measured under nonhydrostatic pressure, Journal of Applied Physics, 83, 7567-7575.

Spetzler, H., C. G. Sammis, and R. J. O'Connell, 1972, Equation of state of NaCl: Ultrasonic measurements to $8 \mathrm{kbar}$ and $800 \mathrm{C}$ and static lattice theory, J. Phys. Chem. Solids, 33, 17271750.

Spetzler, H. A., and Yoneda, A., 1993, Performance of the complete travel-time equation of state at simultaneous high pressure and temperature, in Liebermann, R. C., and Sondergeld, C. H., Eds., Schreiber Memorial Symposium Proceedings, Pure and Applied Geophysics, 141, 379-392.

Spetzler, H. A., Chen, G., Whitehead, S., and Getting, I. C., 1993, A new ultrasonic interferometer for the determination of equation of state parameters of sub-millimeter single crystals, in Liebermann, R. C., and Sondergeld, C. H., Eds., Schreiber Memorial Symposium Proceedings, Pure and Applied Geophysics, 141, 341-377. 
Spetzler, H. A., Shen, A., Chen, G., Herrmannsdoerfer, G., Schulze, H., and Weigel, R., 1996, Ultrasonic measurements in a diamond anvil cell, Physics of the Earth and Planetary Interiors, 98, 93-99.

Stenger, T. E., and Trivisonno, J., 1998, Ultrasonic study of the two-step martensitic phase transformation in $\mathrm{Ni}_{2} \mathrm{MnGa}$, Physical Review B, 57, 2735-2739.

Voronov, F. F., Vereschagin L. F., and Goncharova, V. A., 1960, The effect of hydrostatic pressure on the elastic properties of cerium, Sov. Phys. Dokl., 135, 1280.

Wang, Y.B., Durham, W.B., Getting, I.C., and Weidner, D. J., 2003, The deformation-DIA: A new apparatus for high temperature triaxial deformation to pressures up to $15 \mathrm{GPa}$, Rev Sci Instrm, 74 (6): 3002-3011.

Xu, J.-a., and Mao, H.-k., 2000, Moissanite: A window for high-pressure experiments, Science, 290, 783-785.

Zhu, C. F., and Zheng, R. K., 2000, Ultrasonic evidence for magnetoelastic coupling in

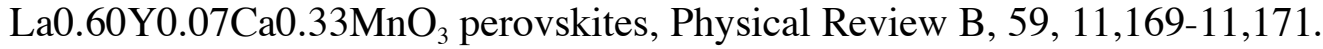




\section{Figure Captions}

Figure 1. Functional block diagram of the electronic components for all three ultrasonic systems.

Figure 2 a,b,c. a) The experimental arrangement for ultrasonic measurements in the moissanite anvil cell. b) The experimental arrangement for ultrasonic measurements in the D-DIA multianvil apparatus. c) The experimental arrangement for ultrasonic measurements in the piston cylinder apparatus. The figures are not to scale and do not show details of mechanical support for clarity.

Figure 3 a,b,c. a) The moissanite anvil cell ready for pressurization. The tubing ascending through the upper center of the photograph supplies the internal gas drive that presses the anvils together. b) The moissanite anvil cell before assembly, showing structural components and the anvils in their radial supports. c) A typical moissanite anvil before use, major diameter $\sim 10 \mathrm{~mm}$.

Figure 4 a,b. a) The D-DIA multi-anvil apparatus assembled and ready for pressurization in it's $400 \mathrm{~T}$ load frame. b) The bottom guide block and anvil assembly removed from the D-DIA to show placement of an ultrasonic transducer on the anvil base.

Figure 5 a,b. a) The hydraulic press used for piston cylinder ultrasonic measurements. The lower ram provides clamping force, and the smaller blue ram drives the piston into the vessel. b) A close up view of the piston cylinder assembly ready for pressurization. The pressure vessel is at the center of the photograph. The piston enters from below.

Figure 6. An example of an E3D simulation of an ultrasonic experiment with the moissanite anvil, beryllium copper gasket and water sample.

Figure 7. Typical waveforms for the high frequency system recorded for an $\sim 3 \mathrm{~mm}$ path in water.

Figure 8. The compressional waveform detected for tantalum at $3 \mathrm{GPa}$ using the configuration of Figure $3 b$ in the LLNL D-DIA.

Figure 9. Ultrasonic data for cerium showing the effects of the phase transition at $\sim 0.76 \mathrm{GPa}$. 


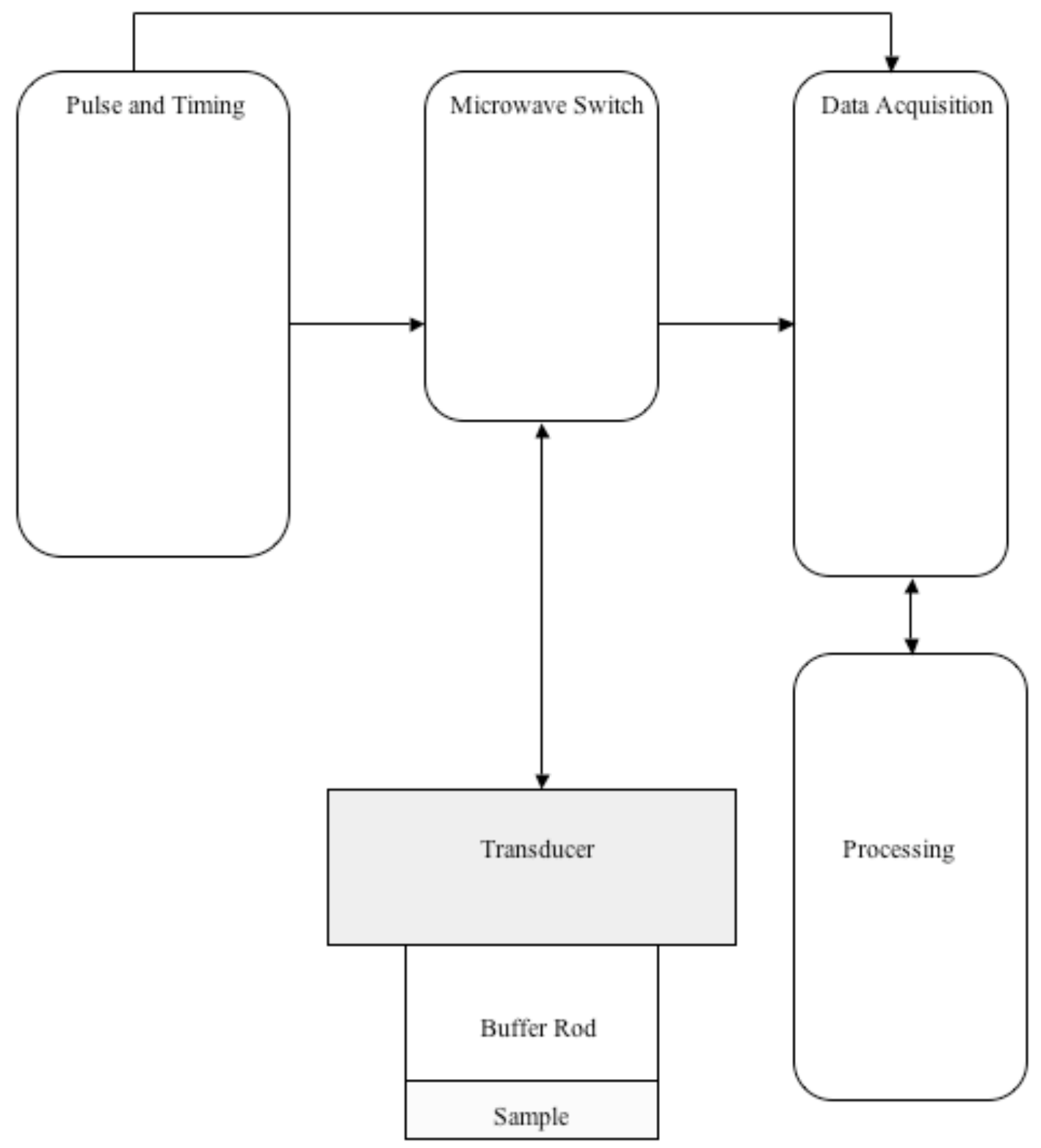

Figure 1. 
Figure 2a
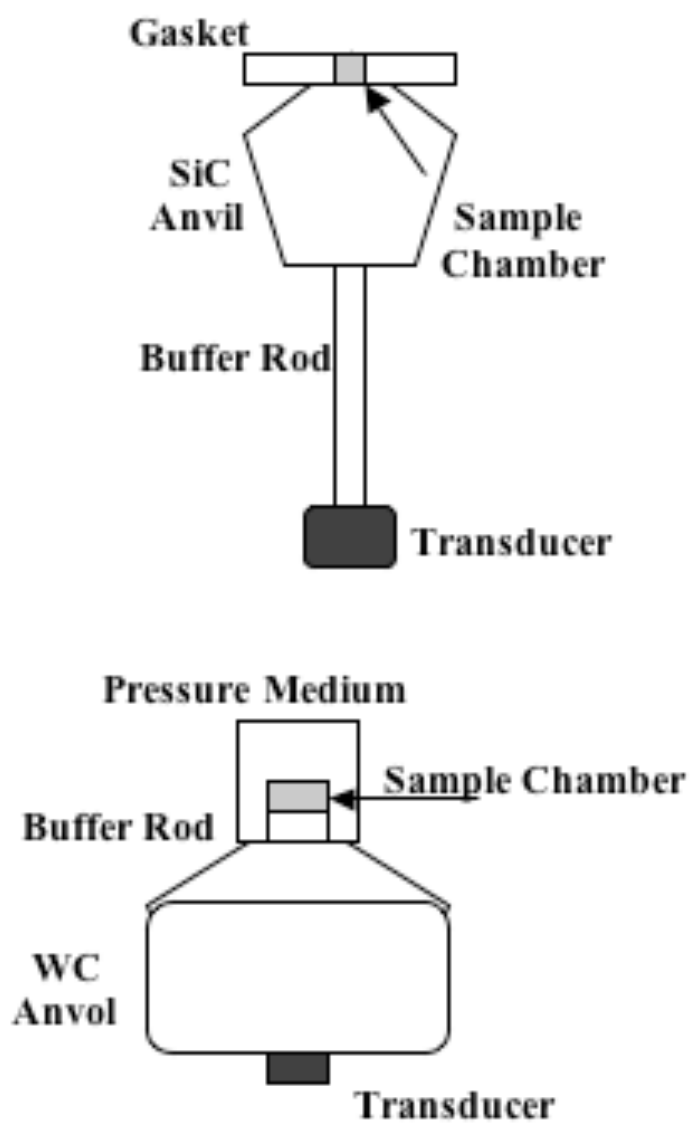

Figure 2 b

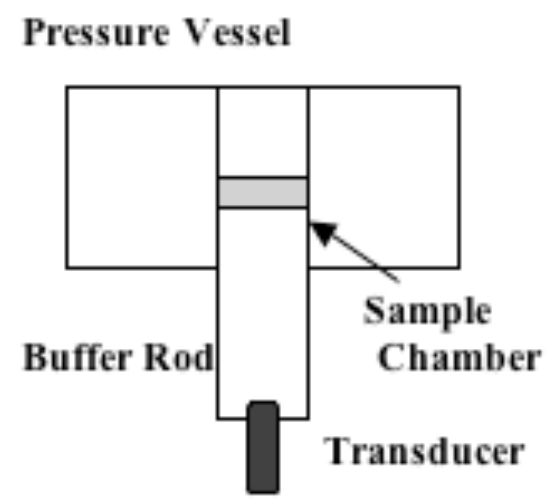

Figure 2c 


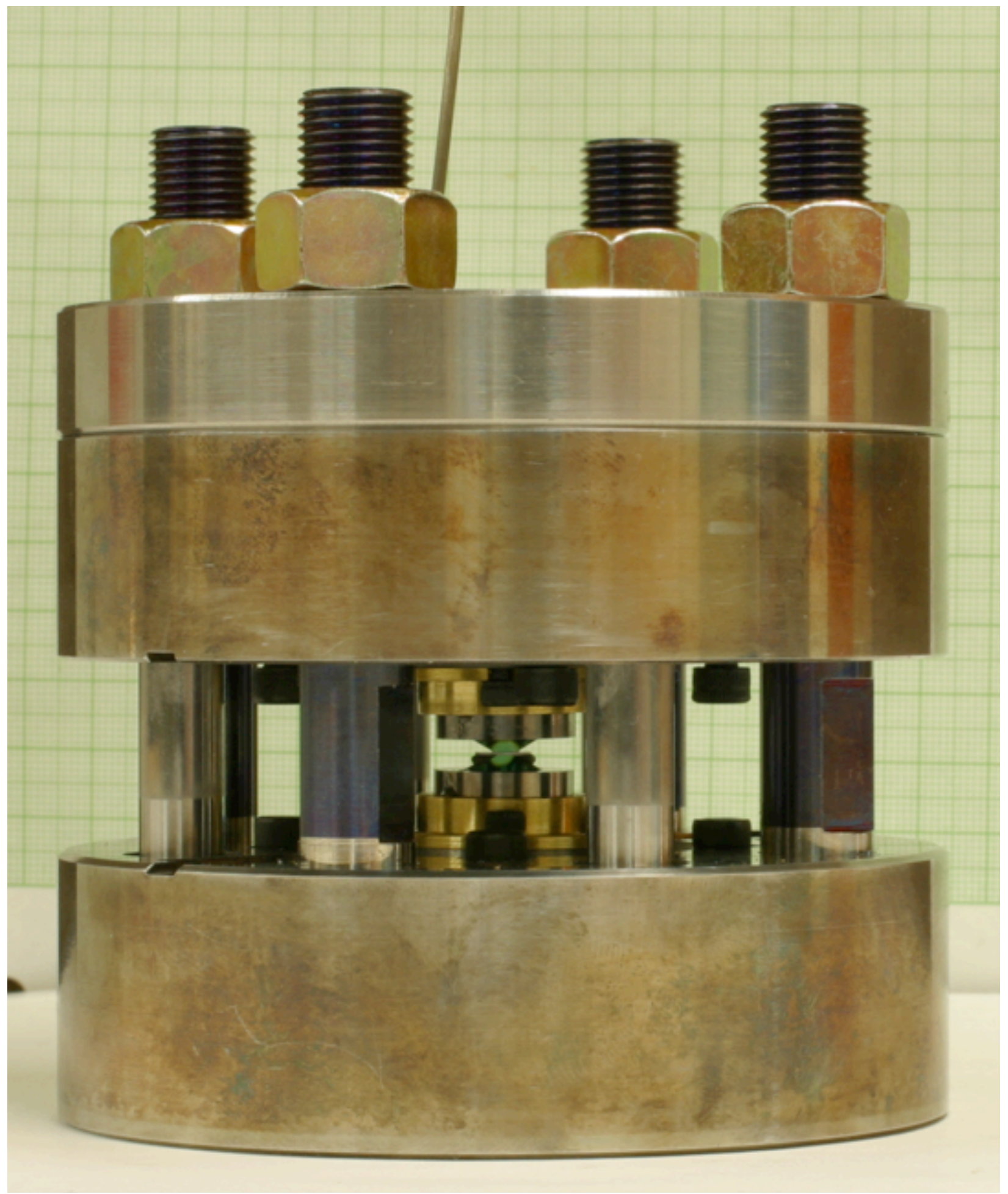

Figure 3a. 


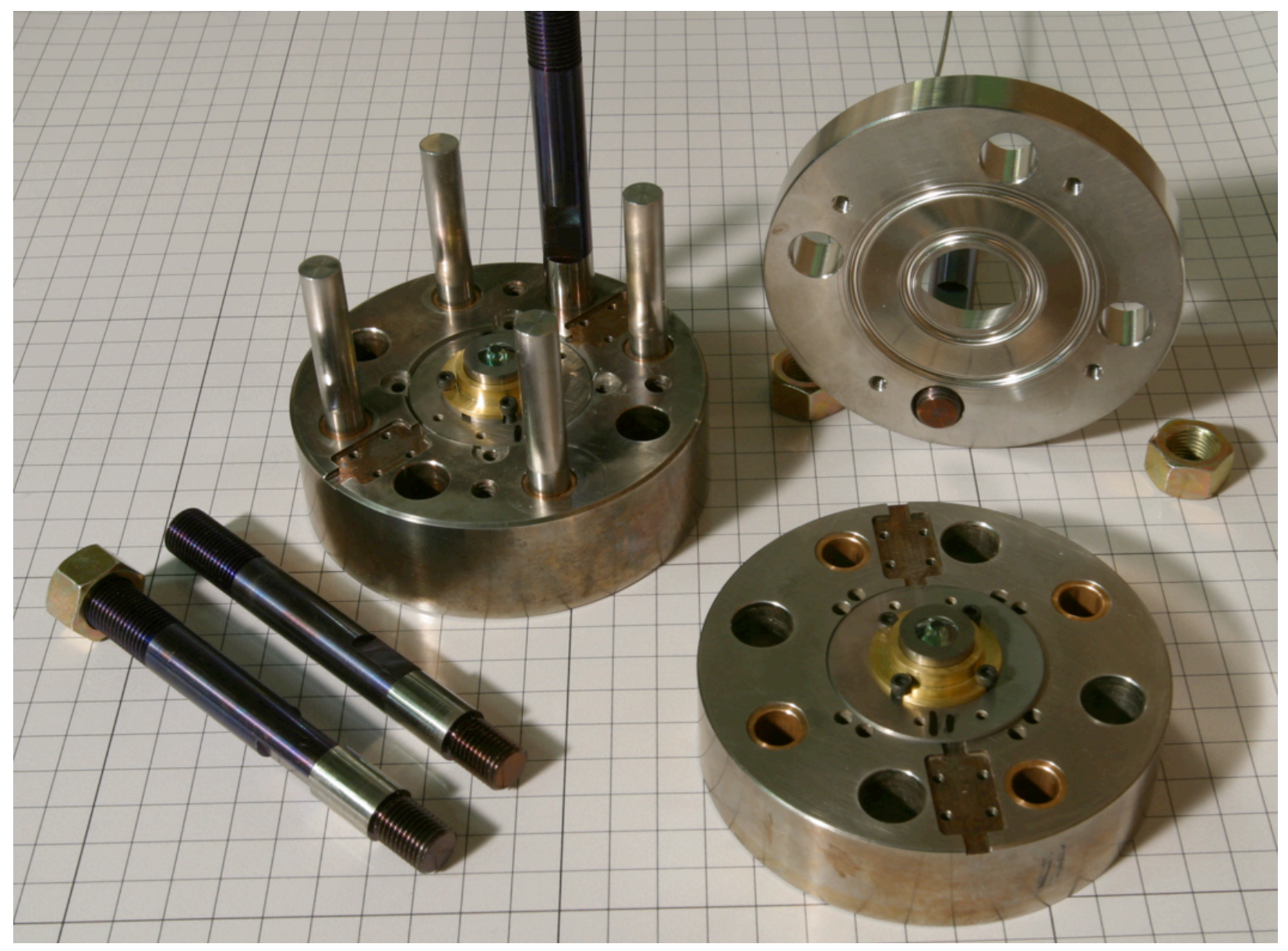

Figure 3b. 


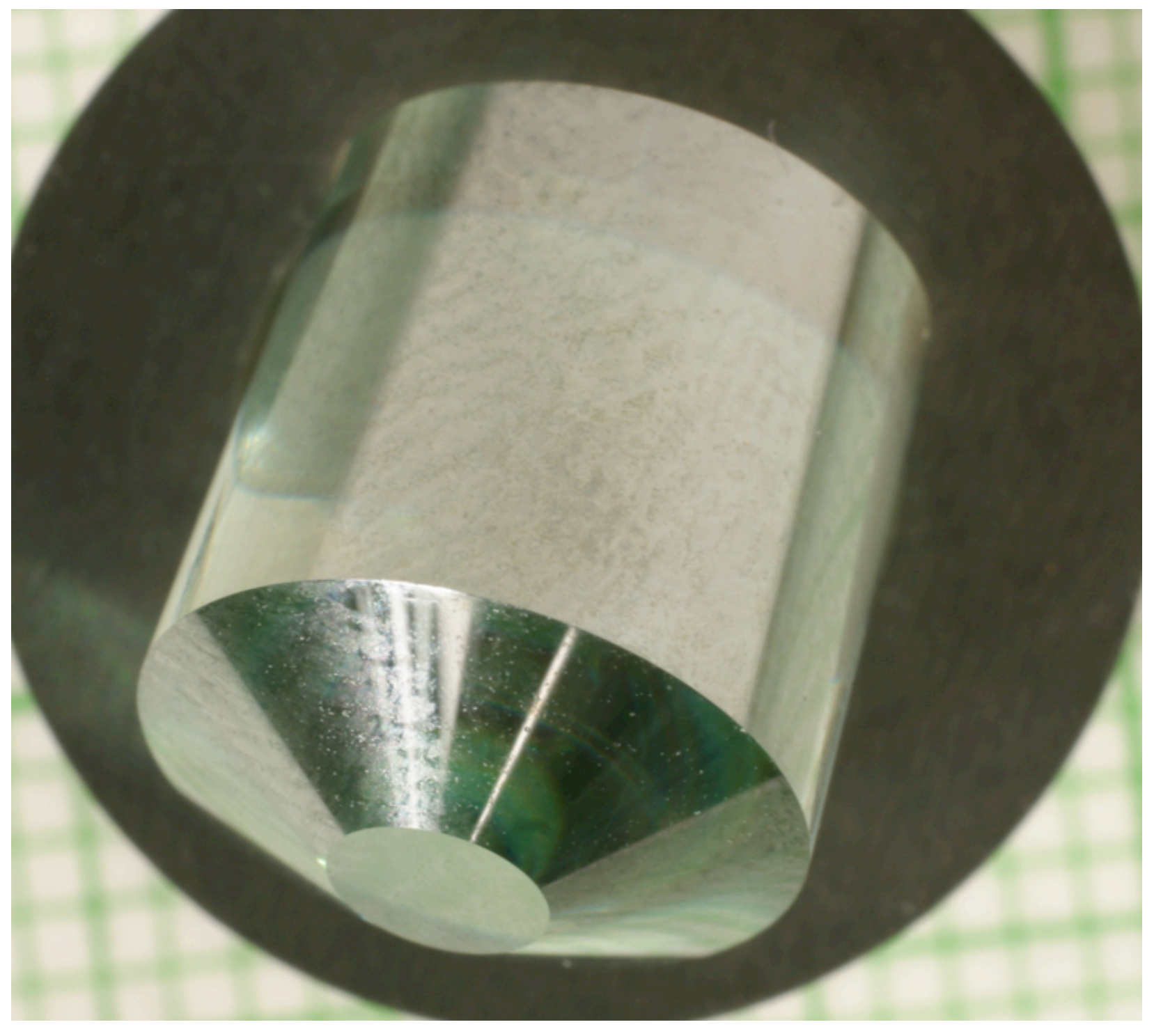

Figure 3c. 


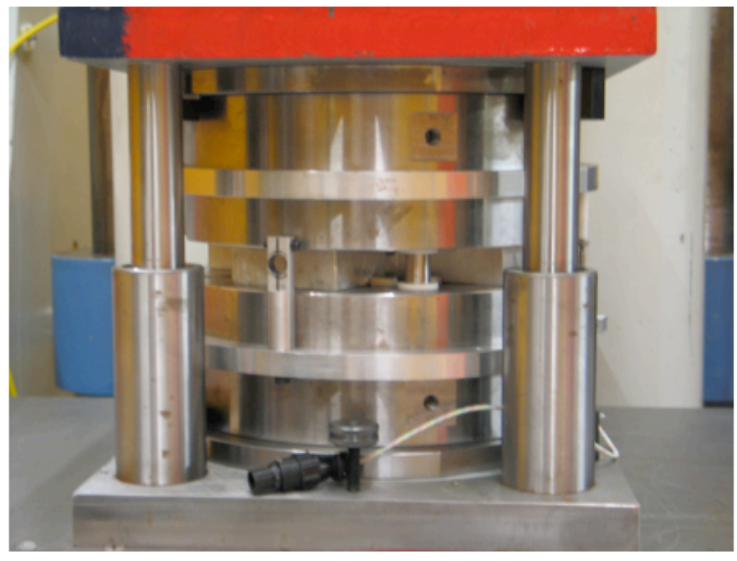

Loading Assembly

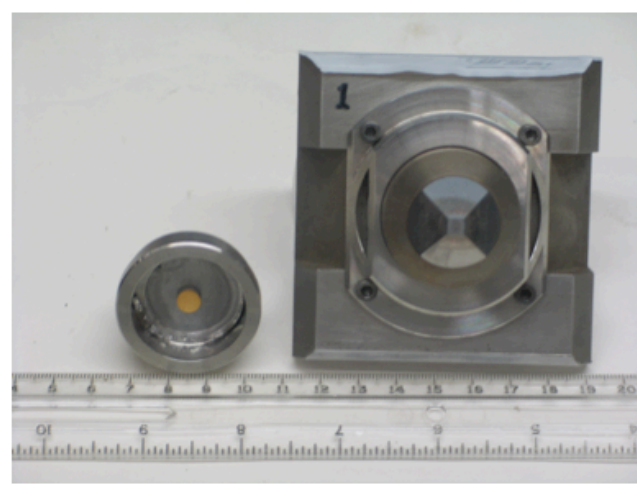

Transducer on WC anvil
Guide block and anvil
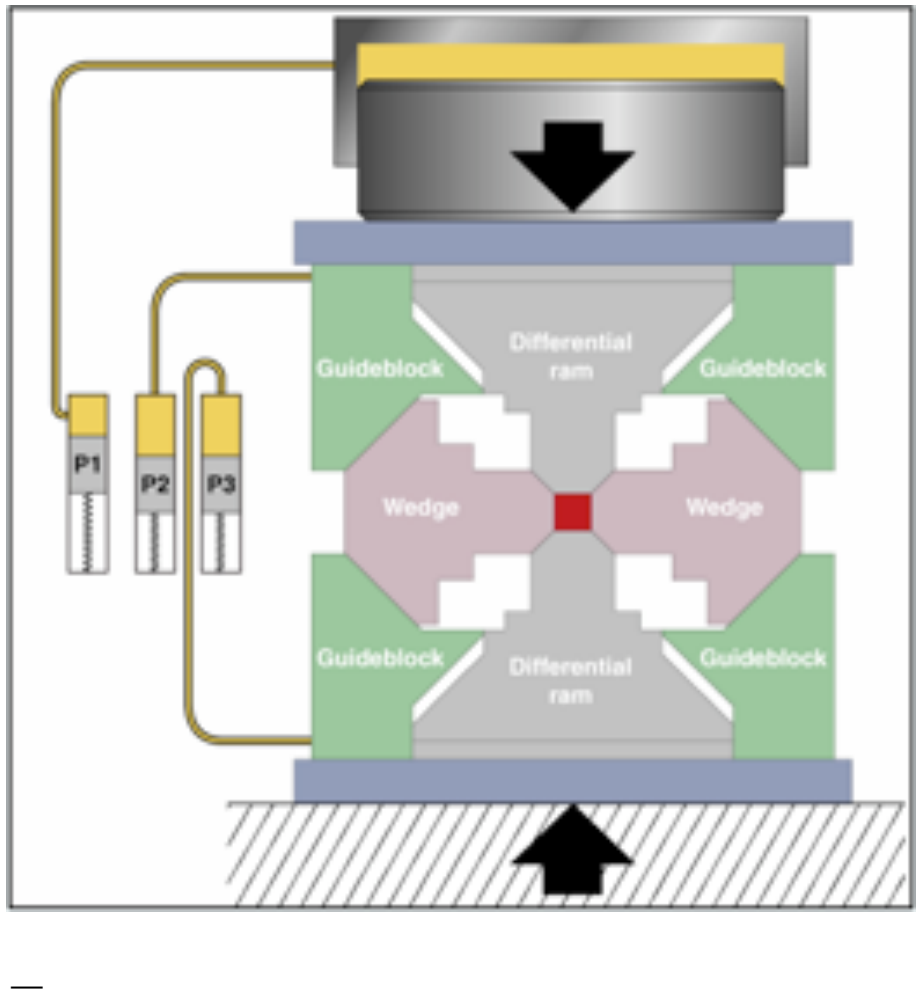

Figure 4 a,b,c. 


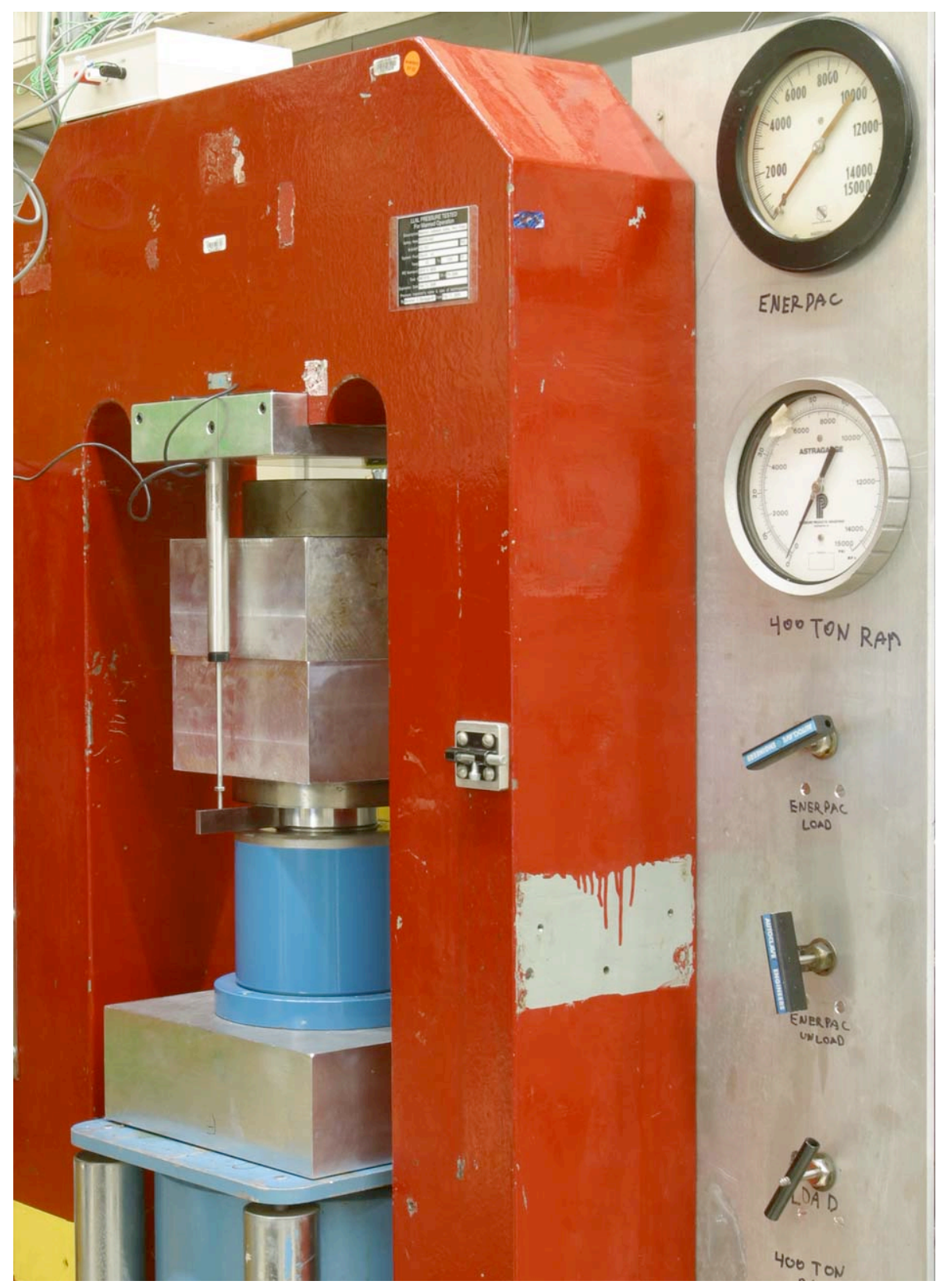

Figure 5 a. 


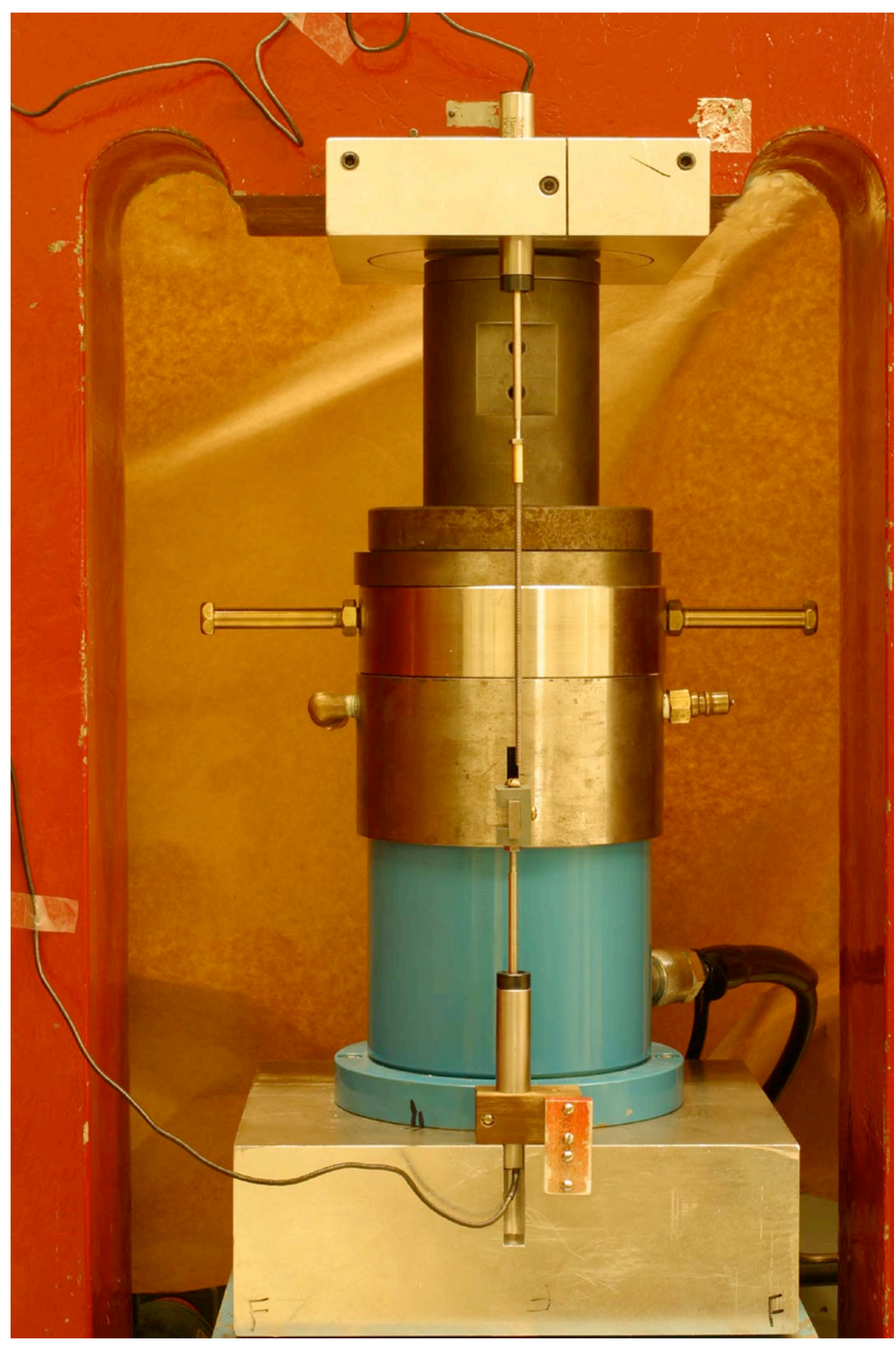

Figure 5b. 


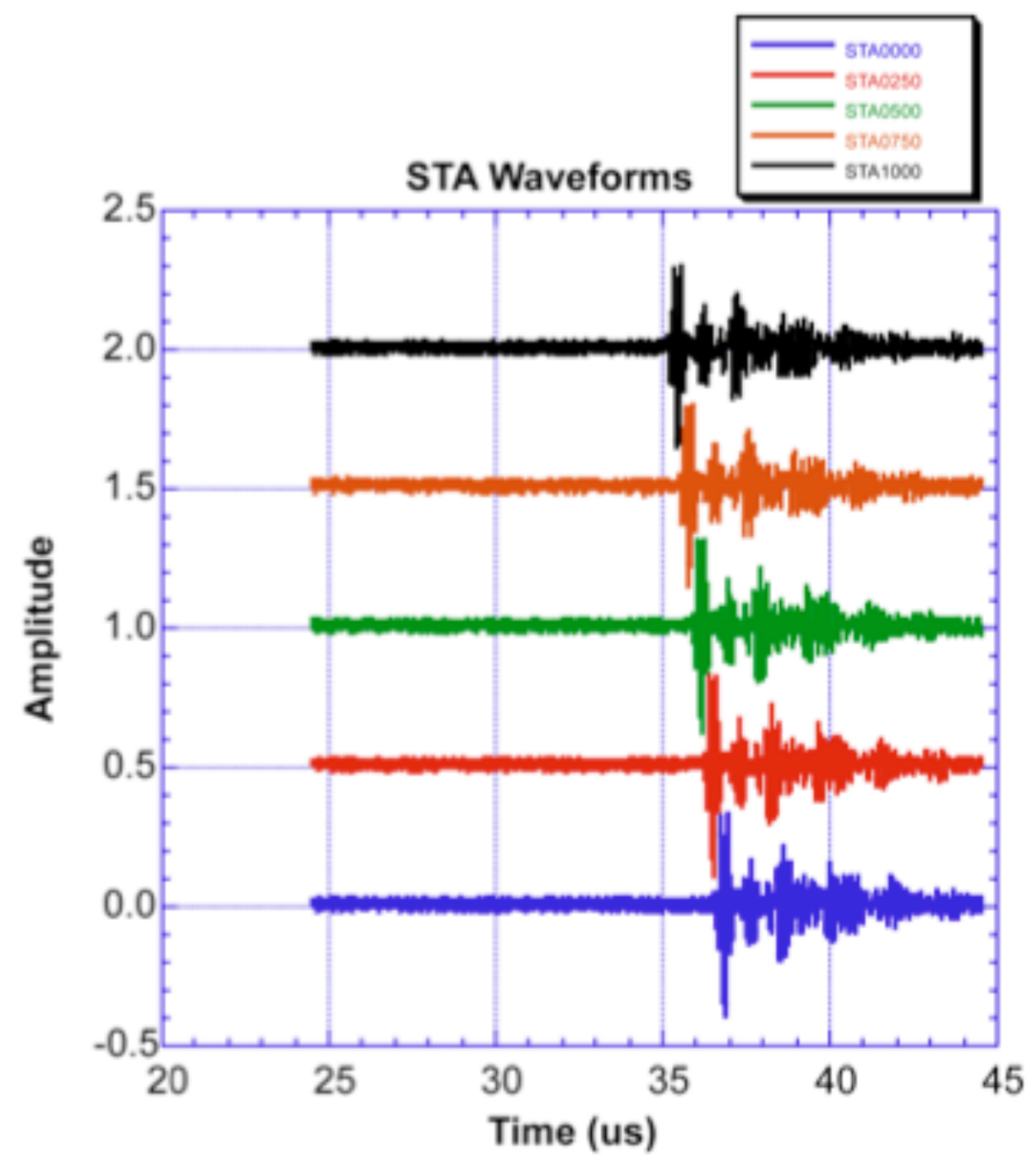

Figure 6. 


\section{Moissanite Piston \\ Beryllium-Copper, Water Sample Media}

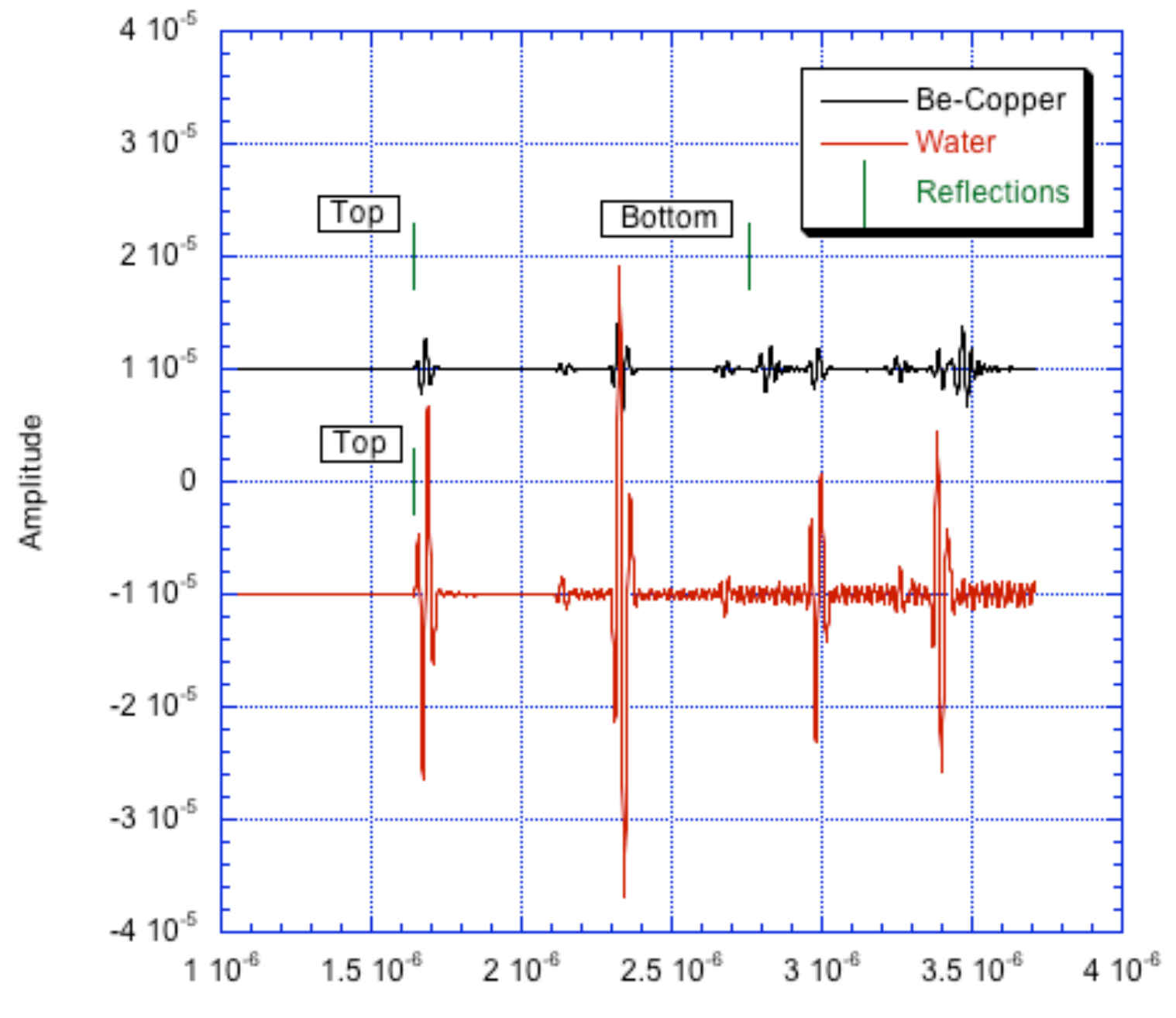

Time (s)

Figure 7. 


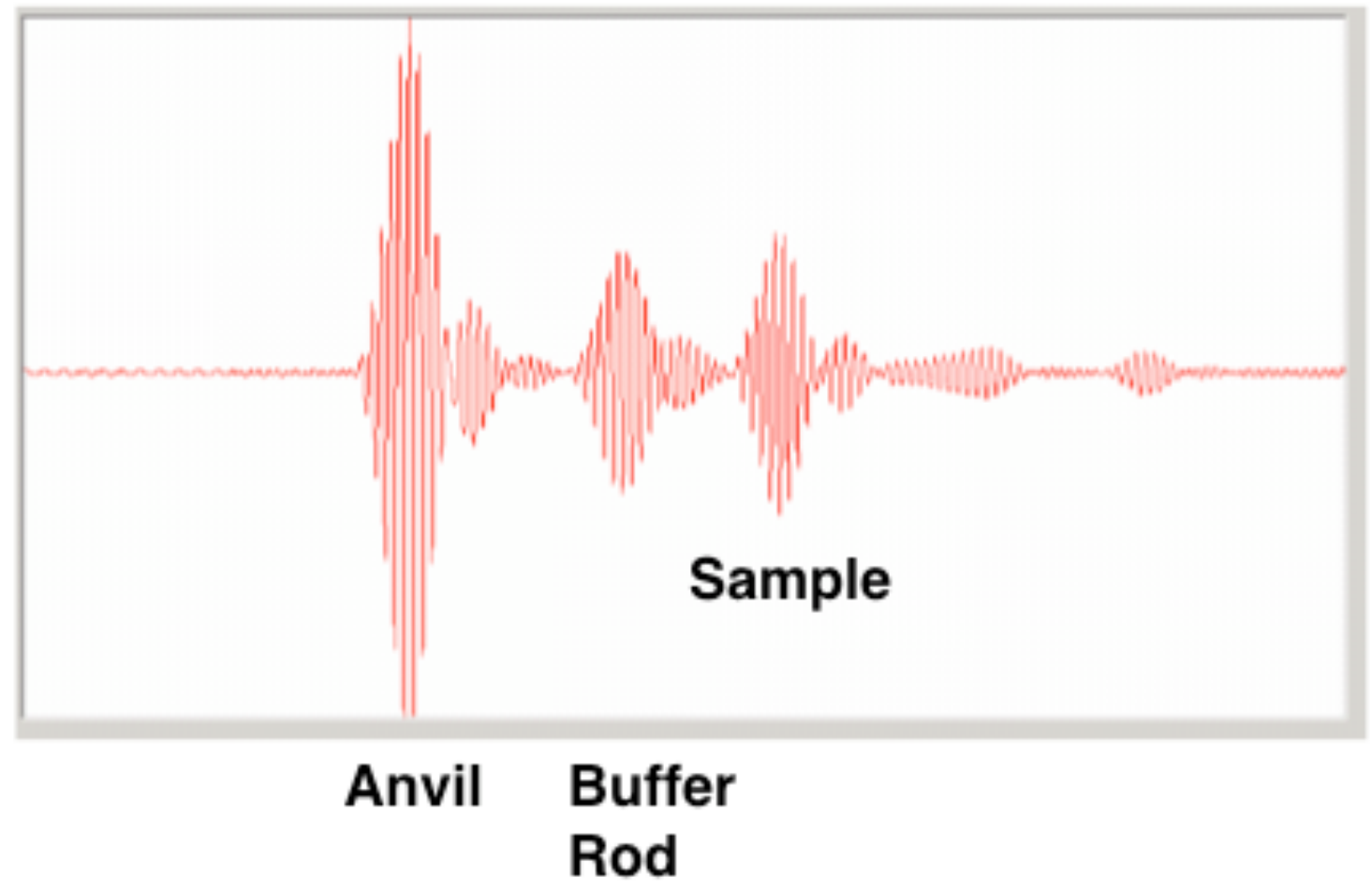

Figure 8. 


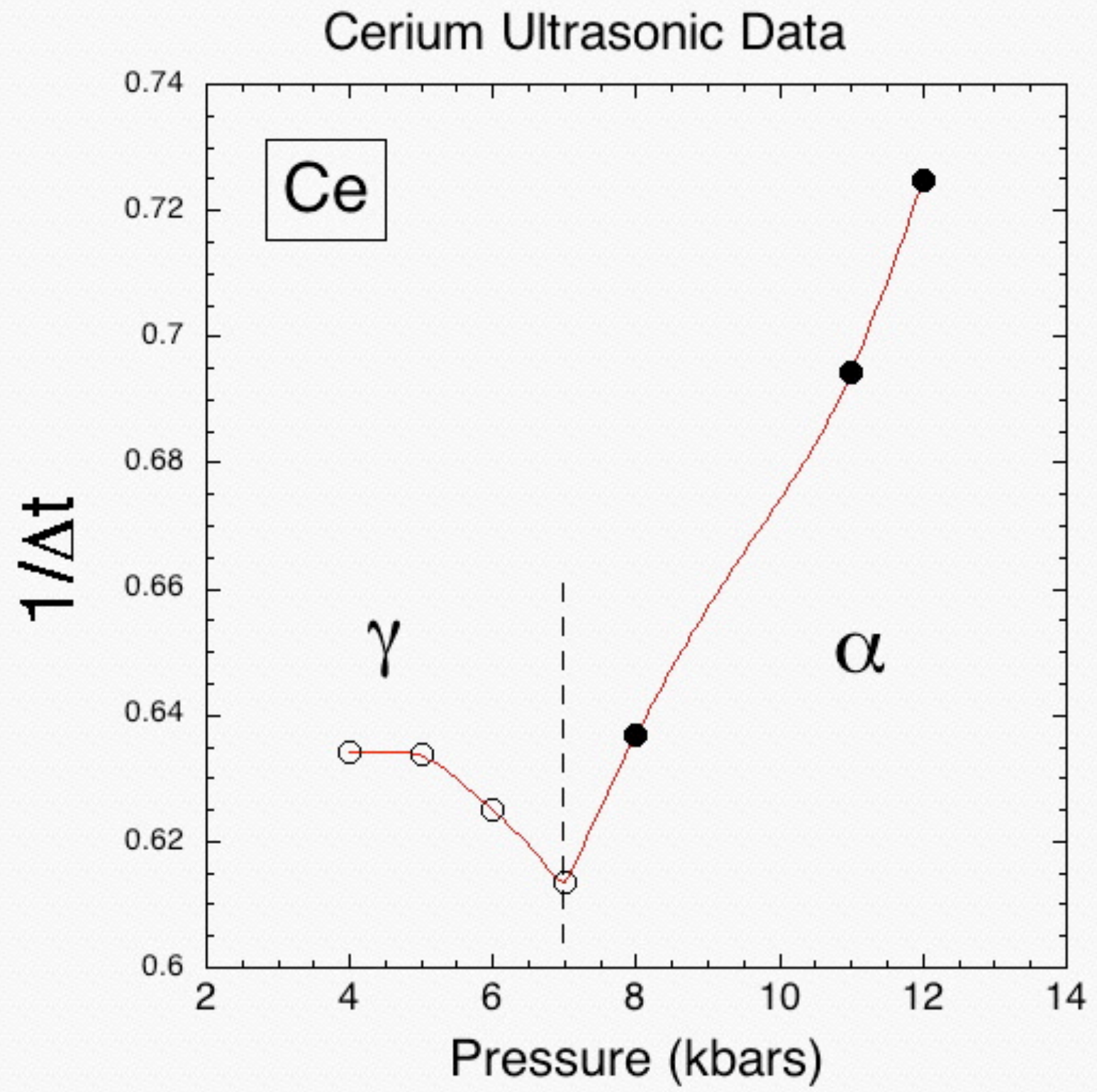

Figure 9. 